\title{
Effectiveness of Anti-TNF $\alpha$ for Crohn Disease: Research in a Pediatric Learning Health System
}

AUTHORS: Christopher B. Forrest, MD, PhD, a,b Wallace V. Crandall, MD, ${ }^{\mathrm{C}}$ L. Charles Bailey, MD, PhD, a,d Peixin Zhang, PhD, ${ }^{a}$ Marshall M. Joffe, MD, MPH, PhD, ${ }^{d}$ Richard B. Colletti,

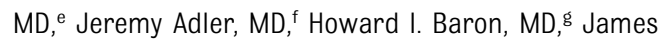
Berman, MD, ${ }^{\text {h }}$ Fernando del Rosario, MD, ${ }^{,}$Andrew B. Grossman, MD, ${ }^{j}$ Edward J. Hoffenberg, MD, ${ }^{k}$ Esther J. Israel, MD,' Sandra C. Kim, MD, ${ }^{\mathrm{c}}$ Jenifer R. Lightdale, MD, MPH, ${ }^{\mathrm{m}}$ Peter A. Margolis, MD, PhD, ${ }^{n}$ Keith Marsolo, PhD, ${ }^{\text {op }}$ Devendra I. Mehta, MD, MS, MRCP, ${ }^{a}$ David E. Milov, MD, ${ }^{r}$ Ashish S. Patel, MD, s,t Jeanne Tung, MD, ${ }^{\text {u }}$ and Michael D. Kappelman, MD, MPH ${ }^{\mathrm{v}}$

aDepartment of Pediatrics, and 'Division of Gastroenterology, Hepatology, and Nutrition, Department of Pediatrics, The Children's Hospital of Philadelphia, Philadelphia, Pennsylvania; ${ }^{b}$ Leonard Davis Institute of Health Economics, and ${ }^{d}$ Center for Clinical Epidemiology and Biostatistics, Perelman School of Medicine, University of Pennsylvania, Philadelphia, Pennsylvania ${ }^{c}$ Department of Pediatrics, The Ohio State University College of Medicine, Nationwide Children's Hospital, Columbus, Ohio; ${ }^{e}$ Department of Pediatrics, The University of Vermont College of Medicine, Burlington, Vermont; ${ }^{f}$ Department of Pediatrics and Communicable Diseases, Division of Pediatric Gastroenterology, University of Michigan, Ann Arbor, Michigan; ${ }^{\text {DDepartment }}$ of Pediatrics, University of Nevada School of Medicine, Pediatric Gastroenterology and Nutrition Associates, Las Vegas, Nevada; hAdvocate Children's Hospital, UIC College of Medicine, Loyola University School of Medicine, Chicago, Illinois; 'Department of Pediatrics, Division of Pediatric Gastroenterology Nemours/Alfred I. duPont Hospital for Children, Wilmington, Delaware; kDepartment of Pediatrics, University of Colorado School of Medicine and Children's Hospital Colorado, Aurora, Colorado; 'Department of Pediatrics, Massachusetts General Hospital for Children, Harvard Medical School, Boston, Massachusetts; ${ }^{m}$ Department of Medicine, Boston Children's Hospital, Boston, Massachusetts; ' ${ }^{D}$ epartment of Pediatrics, James M. Anderson Center for Health Systems Excellence, and ${ }^{\circ}$ Division of Biomedical Informatics, Cincinnati Children's Hospital Medical Center, Cincinnati, Ohio; ${ }^{p}$ Department of Pediatrics, University of Cincinnati College of Medicine, Cincinnati, Ohio; aDepartment of Pediatrics, Arnold Palmer Hospital for Children, Florida State University, Orlando, Florida; 'rDepartment of Pediatrics, Nemour's Children's Hospital, Orlando, Florida; 'Department of Pediatrics, The University of Texas Southwestern Medical Center, Dallas, Texas; ${ }^{t}$ Department of Pediatrics, Children's Medical Center, Dallas, Texas; "Department of Pediatric and Adolescent Medicine, Department of Gastroenterology and Hepatology, Mayo Clinic, Rochester, Minnesota; and 'Department of Pediatrics, University of North Carolina at Chapel Hill, Chapel Hill, North Carolina (Continued on last page)
WHAT'S KNOWN ON THIS SUBJECT: Studies on adult patients who have Crohn disease have shown a comparative benefit of antiTNF $\alpha$ versus placebo and thiopurines. These same studies have not been done in children, because of time, cost, and ethical (withholding an efficacious treatment) challenges.

WHAT THIS STUDY ADDS: Anti-TNF $\alpha$ therapy administered in routine practice to children with Crohn disease was more effective than usual care at achieving clinical and corticosteroid-free remission. Using data from the ImproveCareNow learning health system for observational research is feasible and produces valuable evidence.
OBJECTIVES: ImproveCareNow (ICN) is the largest pediatric learning health system in the nation and started as a quality improvement collaborative. To test the feasibility and validity of using ICN data for clinical research, we evaluated the effectiveness of anti-tumor necrosis factor- $\alpha$ (anti-TNF $\alpha$ ) agents in the management of pediatric Crohn disease (CD). METHODS: Data were collected in 35 pediatric gastroenterology practices (April 2007 to March 2012) and analyzed as a sequence of nonrandomized trials. Patients who had moderate to severe CD were classified as initiators or non-initiators of anti-TNF $\alpha$ therapy. Among 4130 patients who had pediatric CD, 603 were new users and 1211 were receiving anti-TNF $\alpha$ therapy on entry into ICN.

RESULTS: During a 26-week follow-up period, rate ratios obtained from Cox proportional hazards models, adjusting for patient and disease characteristics and concurrent medications, were 1.53 (95\% confidence interval [Cl], 1.20-1.96) for clinical remission and $1.74(95 \% \mathrm{Cl}$, 1.33-2.29) for corticosteroid-free remission. The rate ratio for corticosteroid-free remission was comparable to the estimate produced by the adult SONIC study, which was a randomized controlled trial on the efficacy of anti-TNF $\alpha$ therapy. The number needed to treat was $5.2(95 \% \mathrm{Cl}, 3.4-11.1)$ for clinical remission and 5.0 (95\% $\mathrm{Cl}, 3.4-10.0)$ for corticosteroid-free remission.

CONCLUSIONS: In routine pediatric gastroenterology practice settings, anti-TNF $\alpha$ therapy was effective at achieving clinical and corticosteroidfree remission for patients who had Crohn disease. Using data from the ICN learning health system for the purpose of observational research is feasible and produces valuable new knowledge. Pediatrics 2014; $134: 37-44$ 
Over the last several decades, therapeutic advances in the treatment of pediatric Crohn disease (CD) have included the widespread use of immunomodulators such as 6-mercaptopurine, azathioprine, and methotrexate. ${ }^{1-3}$ More recently, the anti-tumor necrosis factor $\alpha$ (anti-TNF $\alpha$ ) biological agents (eg, infliximab and adalimumab) have been adopted as a treatment of moderate to severe pediatric CD. ${ }^{4}$ Although several studies on adult patients who have $C D$ have shown a comparative benefit of anti-TNF $\alpha$ versus placebo ${ }^{5}$ and thiopurines, ${ }^{6}$ these same studies have not been done in children because of practical (time and cost) and ethical (withholding an efficacious treatment) challenges.

The cost of anti-TNF $\alpha$ is in the range of tens of thousands of dollars per year, and the long-term direct and indirect costs are substantial. ${ }^{7}$ Administration of anti-TNF $\alpha$ has been associated with serious infections, hepatic T-cell lymphomas, systemic lupus, and blood disorders. ${ }^{8}$ Variation in the management of pediatric patients who have CD results in part from a paucity of evidence on how to best treat patients who have this disorder. ${ }^{9-11}$ The costs, risks, and treatment variability of anti-TNF $\alpha$ therapy are key reasons it was selected as 1 of the Institute of Medicine's top 25 comparative effectiveness research priorities. ${ }^{12}$

To address the lack of information on the effectiveness of anti-TNF $\alpha$ therapy for moderate to severe pediatric $\mathrm{CD}$, we conducted a study to evaluate use of these agents to induce remission among children managed in pediatric gastroenterology practices. Similar to pragmatic clinical trials, which assess the effectiveness of therapies in unselected patients, ${ }^{13}$ our study contrasted initiation of biologic therapy among pediatric patients who had moderate to severe CD with usual care, which may involve any combination of thiopurines, methotrexate, corticosteroids, 5-aminosalicylates, nutrition therapy, and surgery.
The study was done in ImproveCareNow (ICN), which started as a quality improvement collaborative and is becoming a national, distributed learning health system. A learning health system is organized around communities of patients, clinicians, and researchers who work together to purposefully integrate knowledge generation (research) with knowledge dissemination and implementation at the point-of-care (quality improvement). ${ }^{14-19}$

ICN has included a chronic disease registry since 2007. Initially, it was used expressly for quality improvement. We sought to test the feasibility and validity of using these data for comparative effectiveness research. In addition to estimating treatment effects, we contrasted our results with those reported in 2 controlled trials: an anti-TNF $\alpha$ efficacy study done with pediatric patients (the REACH study ${ }^{4}$ ) and a comparative study of anti-TNF $\alpha$ versus thiopurines done with adult patients (the SONIC study6).

\section{METHODS}

\section{Study Setting}

ICN was established in 2007 to improve the health and health care of children who have inflammatory bowel disease (IBD) ${ }^{20,21}$ Participating pediatric gastroenterology practices enrolled patients in an IBD registry, collected data at each outpatient visit, conducted quality improvement activities, and participated in research. Although sites worked to provide highly reliable care through the use of quality improvement methodology adapted to local circumstances, specific therapeutic choices were at the discretion of physicians.

We created a research dataset from the ICN registry by encrypting patient, physician, and practice identifiers and offsetting dates by a patient-specific randomly generated constant. The Children's Hospital of Philadelphia's Institutional Review Board deemed this research exempt from continuing review. The registry comprised longitudinal records of clinical care and health status collected during outpatient encounters and entered via a web-portal into a central database. Data elements included symptoms, results of physical examinations, laboratory values, physician assessments, and prescribed therapies. To standardize data collection, all sites were trained in the use of the case report form. Select data issues were reviewed at semi-annual in-person meetings, monthly webinars, and via listserv.

This study used ICN registry data collected from April 2007 to March 2012. A total of 35 pediatric gastroenterology practices enrolled 6402 patients who had IBD; of these, there were 4130 (65\%) patients who had CD who made 20456 visits.

\section{Disease Activity}

For each visit, clinicians recorded the components of the Short Pediatric Crohn's Disease Activity Index (sPCDAl) ${ }^{22}$ and a Physician Global Assessment rating of disease severity (from 1 [inactive] to 4 [severe disease]). The sPCDAl used 6 of the 11 components from the full PCDAl, ${ }^{23}$ including abdominal pain, stools, weight loss, abdominal examination, extraintestinal manifestations, and general well-being. The SPCDAl has comparable discriminatory accuracy for categorizing disease severity as the full PCDAl. ${ }^{22}$ Based on the scoring conventions for the full PCDAl, we defined moderate to severe disease as a sPCDAl score $\geq 30$, and clinical remission as a score $<10$. A remission was considered corticosteroidfree if a visit satisfied the clinical remission criterion and the patient was not taking oral corticosteroids at any dose. We did not evaluate whether corticosteroidfree remission was sustained.

\section{Missing Data}

Across the full dataset $8 \%$ of the SPCDAl components were missing; $41 \%$ of visits 
had at least 1 missing component. To address this problem, we implemented multiple imputation (MI) using the SAS procedure MI (SAS Institute, Inc, Cary, NC). MI provides a range of reasonable predictions for missing data. Inferences obtained from multiply imputed data account for both the missing data and the uncertainty of the imputations. ${ }^{24-26}$

We implemented $\mathrm{Ml}$ by creating 100 replicates of the dataset. The imputation procedure fit a discriminant model, which is appropriate for categorical data such as the sPCDAl components. ${ }^{27}$ The independent variables in the discriminant models were age, gender, race (white, black, other), disease phenotype (inflammatory, stricturing, or penetrating), disease location (ileum, colon, and upper tract), concurrent medications (thiopurines, methotrexate, 5-aminosalicylates, and oral corticosteroids), Physician Global Assessment of disease severity, practice site, and duration of disease. Once missing components were imputed, we computed the sPCDAl score. The trials were formed and statistical models run separately for each replicate, and then results were pooled to obtain single treatment estimates.

\section{Trial Formation}

We conceptualized the registry dataset as a sequence of nonrandomized trials in which anti-TNF $\alpha$ therapy was initiated or not initiated. ${ }^{28}$ This sequentialtrials strategy allows a patient to contribute $>1$ trial to the analysis, which makes greatest use of available data. ${ }^{28,29}$ To be eligible as a first visit in an initiator trial (ie, the baseline visit), the patient had to be a new user of anti-TNF $\alpha$ (either infliximab or adalimumab) therapy. All visits made by patients who never used biologic therapy were potential non-initiator baseline visits. Among users of biologic therapy, visits that occurred before the start of biologic initiation were potential starting points for noninitiator trials.

Eligibility criteria for baseline visits for all trials were age $<21$ years and moderate to severe disease severity (sPCDAl score $\geq 30$ ). Trials also included a visit during the follow-up period, which began at 2 weeks and concluded at 26 or 52 weeks, and at least 1 visit before the start of the trial. We applied the trial selection criteria to the 100 replicates of the dataset. Because some of the SPCDAl components were imputed by using MI, the SPCDAl values varied across replicates; thus, trials could meet the inclusion criteria of SPCDAl $\geq 30$ in some but not other replicates. The number of trials ranged from 232 to 252 per replicate, with a mean of 241 for initiators, and 1147 to 1210 per replicate, with a mean of 1182 for non-initiators. Across the 100 replicates, patients contributed 1.9 trials on average.

\section{Statistical Analyses}

Outcomes for trials (clinical remission or corticosteroid-free remission) were evaluated regardless of whether patients subsequently altered therapy. This approach makes use of the intention-to-treat principle. We conducted bivariate analyses to test the comparability between initiator and non-initiator trials on patient, disease, and pharmacological treatment characteristics measured at baseline. These were implemented with logistic (categorical covariates) or linear (continuous covariates) regression models that regressed type of trial (initiator versus non-initiator) on 1 covariate and obtained robust variance estimates, accounting for clustering of trials within a patient, for the differences in proportions or means.

We computed the unadjusted probability of achieving remission during 26 or 52 weeks of follow-up. We adjusted the probability of achieving remission by using the generalized estimating equation (GEE), clustering on patients, with a logit link function, and adjusted for patient age in years, gender (male, female), race (white, black, other), disease phenotype (inflammatory, stricturing, penetrating), location of disease (ileum, colon, upper tract; all yes/no indicators), time since $C D$ diagnosis $(<1$ year vs $\geq 1$ year $)$, and medication use (thiopurines, methotrexate, 5-aminosalicylates, and corticosteroids; all yes/no indicators).

We estimated rate ratios by fitting a Cox proportional hazards model, with time since the start of the trial as the time variable, and adjusted for the covariates used in the GEE models. Separate models were fit with 26- and 52-week durations of follow-up.

To evaluate the timing of the effect of biologics on induction of remission, we plotted the cumulative probability of remission and corticosteroid-free remission as a function of time. We estimated the cumulative probability of the outcomes by week of follow-up for the 100 imputed replicates and averaged these values to create the plots.

To estimate a number needed to treat (NNT), we extended the trials to include a 26-week pre-trial observation period. This Iongitudinal analysis contrasted the within-subjects pre-post change between the 2 treatment groups. We fit the generalized estimating equation, clustering on patient, and regressed the outcome on covariates and a 4category variable for treatment group (initiator or non-initiator) by time period (pre or post). The treatment effect estimate contrasted the average triallevel probability of remission from the pre- to the post-period in the initiator versus non-initiator groups. The NNT was computed as the reciprocal of the absolute percentage difference between the 2 groups ${ }^{30}$; we also computed $95 \%$ confidence intervals (Cl) for the NNTs. ${ }^{31}$ 
Some trials were censored at their last visit because the treatment outcome was not achieved during the observation period. Among these rightcensored trials, we identified those with a visit 27 to 52 weeks after the start of the trial and used linear interpolation to assign a sPCDAl score at 26 weeks and then re-estimated treatment effects. We also re-estimated treatment effects using the single-item Physician Global Assessment, which was present for $96 \%$ of pediatric CD visits.

\section{Comparison With REACH and SONIC}

We applied the REACH selection criteria to initiator trials, ${ }^{4}$ which involved restricting the sample to those who started anti-TNF $\alpha>3$ months after diagnosis and were receiving thiopurines and/or methotrexate at the time of trial initiation. Although REACH assessed remission at 10 weeks, we allowed assessment to occur as late as 16 weeks to account for variation in visit frequency.

We reanalyzed the SONIC study of adult CD patients 6 by combining its anti-TNF $\alpha$ treatment arms (anti-TNF $\alpha$ only and anti-TNF $\alpha$ with thiopurine), computing the 26-week corticosteroid-free remission rate, and estimating a rate ratio using the thiopurine-only group as the referent. We contrasted these results with our study's estimates.

\section{RESULTS}

Among the pediatric patients who had CD in our sample, 1814 received antiTNF $\alpha$ therapy, and of these, 603 started therapy during the time of the study. There were 2316 patients who never used anti-TNF $\alpha$ therapy.

Patient and disease characteristics and concurrent medications at the baseline visit of trials are shown in Table 1. Noninitiator trials were more likely to begin with thiopurines, 5-aminosalicylates, and corticosteroids. Physicians rated disease severity as higher for the initiator trials, despite sPCDAl scores comparable to the non-initiator trials.

By 26 weeks, initiator trials had a $54.4 \%$ chance of achieving remission, whereas non-initiators had a $41.2 \%$ chance (Table 2). Also, by 26 weeks, initiators had a $47.3 \%$ chance of achieving corticosteroid-free remission vs $31.2 \%$ for non-initiators. Adjusting for patient and disease characteristics and baseline medications produced comparable remission rate estimates to unadjusted analyses.

The remission rate ratios for 26 and 52 weeks of follow-up were similar in unadjusted and adjusted analyses (Table 3). Initiator trials were $\sim 50 \%$ more likely to achieve clinical remission and $70 \%$

TABLE 1 Baseline Characteristics (ie, First Visit for Each Trial) for Anti-TNF $\alpha$ Initiator and NonInitiator Trials

\begin{tabular}{|c|c|c|c|}
\hline \multirow[t]{2}{*}{ Characteristic } & Initiator Trials & Non-Initiator Trials & $P$ \\
\hline & \multicolumn{3}{|c|}{$\%(95 \% \mathrm{Cl})$} \\
\hline \multicolumn{4}{|l|}{ Patient gender } \\
\hline Male & $51.4(44.9-57.9)$ & $50.8(45.9-55.8)$ & \multirow[t]{2}{*}{.88} \\
\hline Female & $48.6(42.1-55.1)$ & $49.2(44.2-54.1)$ & \\
\hline \multicolumn{4}{|l|}{ Patient race } \\
\hline White & $82.3(77.1-87.4)$ & $84.2(80.7-87.7)$ & \multirow[t]{3}{*}{.27} \\
\hline Black & $13.6(8.9-18.2)$ & $10.2(7.4-13.0)$ & \\
\hline Other & $4.2(1.4-6.9)$ & $5.6(3.3-7.9)$ & \\
\hline \multicolumn{4}{|l|}{ Disease phenotype } \\
\hline Inflammatory & $89.0(84.7-93.2)$ & $87.1(83.4-90.8)$ & \multirow[t]{3}{*}{.63} \\
\hline Stricturing & $3.9(1.2-6.6)$ & $5.4(3.0-7.8)$ & \\
\hline Penetrating & $7.1(3.7-10.6)$ & $7.5(4.4-10.5)$ & \\
\hline \multicolumn{4}{|l|}{ Disease locations } \\
\hline Ileum & $72.0(66.1-77.8)$ & $71.5(66.9-76.0)$ & .87 \\
\hline Colon & $86.9(82.5-91.2)$ & $83.7(80.2-87.1)$ & .19 \\
\hline Upper tract & $51.2(44.7-57.7)$ & $52.4(47.4-57.4)$ & .74 \\
\hline \multicolumn{4}{|l|}{ Medications } \\
\hline Thiopurine & $33.8(27.7-39.9)$ & $59.6(55.6-63.5)$ & $<.01$ \\
\hline Methotrexate & $10.1(6.2-13.9)$ & $6.8(4.8-8.8)$ & .12 \\
\hline 5-Aminosalicylate & $35.3(29.1-41.5)$ & $49.5(45.2-53.8)$ & $<.01$ \\
\hline \multirow[t]{2}{*}{ Corticosteroid } & $27.2(21.5-33.0)$ & $43.4(39.6-47.1)$ & $<.01$ \\
\hline & \multicolumn{2}{|c|}{ Mean $(95 \% \mathrm{Cl})$} & \\
\hline Age (y) & $14.9(14.5-15.4)$ & $14.6(14.3-15.0)$ & .24 \\
\hline Weight (kg) & $51.3(49.0-53.5)$ & $49.9(48.1-51.7)$ & .30 \\
\hline Height $(\mathrm{cm})$ & $157.9(155.6-160.2)$ & $155.9(154.0-157.8)$ & .14 \\
\hline Disease duration (y) & $2.8(2.4-3.1)$ & $2.7(2.5-3.0)$ & .75 \\
\hline sPCDAl score & $41.9(40.4-43.4)$ & $41.1(40.4-41.8)$ & .36 \\
\hline Physician Global Assessment & $2.7(2.6-2.8)$ & $2.4(2.3-2.4)$ & $<.01$ \\
\hline C-reactive protein $(\mathrm{mg} / \mathrm{L})^{\mathrm{a}}$ & $4.8(3.2-6.4)$ & $5.3(4.1-6.4)$ & .64 \\
\hline Erythrocyte sedimentation rate $(\mathrm{mm} / \mathrm{h})^{\mathrm{a}}$ & $28.5(25.2-31.9)$ & $24.5(22.6-26.5)$ & .03 \\
\hline Albumin $(g / d L)^{a}$ & $3.9(3.8-3.9)$ & $3.9(3.9-4.0)$ & .13 \\
\hline Hematocrit (\%) ${ }^{\mathrm{a}}$ & $36.1(35.4-36.9)$ & $36.9(36.5-37.2)$ & .07 \\
\hline
\end{tabular}

a 0 average across the 100 replicates, C-reactive protein values were available for $54 \%$ of initiator and $50 \%$ of non-initiator trials, erythrocyte sedimentation rate for $77 \%$ of initiator and $68 \%$ of non-initiator trials, albumin for $77 \%$ of initiator and $73 \%$ of non-initiator trials, and hematocrit for $81 \%$ of initiator and $78 \%$ of non-initiator trials. 
TABLE 2 Percentage of Trials Achieving Remission and Corticosteroid-Free Remission During 26And 52-Week Follow-up Periods

\begin{tabular}{lccr}
\hline \multicolumn{1}{c}{ Outcome } & Duration of Follow-up & Initiator Trials & Non-Initiator Trials \\
\cline { 3 - 4 } & & & \% Achieving Outcome $(95 \% \mathrm{Cl})$ \\
\hline Unadjusted & & & \\
$\quad$ Clinical remission & $26 \mathrm{wk}$ & $54.4(47.7-61.1)$ & $41.2(38.2-44.2)$ \\
& $52 \mathrm{wk}$ & $66.6(60.3-72.8)$ & $56.2(53.2-59.3)$ \\
Corticosteroid-free remission & $26 \mathrm{wk}$ & $47.3(40.6-53.9)$ & $31.2(28.4-34.0)$ \\
& $52 \mathrm{wk}$ & $60.1(53.7-66.5)$ & $47.5(44.5-50.5)$ \\
Adjusted $^{\text {a }}$ & & & \\
Clinical remission & $26 \mathrm{wk}$ & $54.8(47.2-62.4)$ & $40.7(36.5-45.0)$ \\
Corticosteroid-free remission & $52 \mathrm{wk}$ & $67.3(60.1-74.4)$ & $55.6(51.1-60.1)$ \\
& $26 \mathrm{wk}$ & $45.6(38.1-53.1)$ & $30.8(26.8-34.7)$ \\
& $52 \mathrm{wk}$ & $58.8(51.5-66.2)$ & $47.0(42.5-51.5)$ \\
\hline
\end{tabular}

a Proportions were adjusted for patient age, gender, and race, disease location, duration, and phenotype, and concurrent medications, all measured at baseline of the trial.
On average across the 100 imputed replicates, 110 initiator and 695 noninitiator trials were right-censored because they did not achieve remission and did not have a visit at 6 months. We interpolated a sPCDAl value at 26 weeks for these trials and re-estimated the rate ratio for remission, which was $1.54(95 \% \mathrm{Cl}$, 1.23-1.93).

There were an average of 159 initiator and 897 non-initiator trials in the 100 imputed replicates for analyses that involved a 26-week observation period before trial initiation and 26-week follow-up interval (ie, post-period). On average, the chances of remission for initiators were $32.6 \%$ higher in the postperiod compared with the pre-period, whereas the post-pre change for non-initiators was just $13.2 \%$. The difference-in-difference treatment effect estimate adjusts the change in the initiator group for the change in the non-initiator group and was $19.4 \%$ (95\% Cl, 9.0-29.8) for clinical remission, an NNT of $5.2(95 \% \mathrm{Cl}, 3.4-11.1)$. The corticosteroid-free remission difference-in-difference estimate was $19.9 \%(95 \% \mathrm{Cl}, 10.0-29.8)$ with an NNT of $5.0(95 \% \mathrm{Cl}, 3.4-10.0)$.

\section{Contrast With REACH and SONIC}

Applying REACH selection criteria 4 to the ICN sample yielded an average of 75 initiator trials across the 100 replicates. The clinical response rates (to be consistent with REACH, defined for ICN as sPCDAl score $<30$ and a minimum decrease of 15) were: REACH $88 \%$ (95\% Cl, 82\%-94\%) ${ }^{4}$ vs ICN $82 \%$ (95\% Cl, 72\%-91\%). The clinical remission rates were: REACH 59\% (95\% Cl, 50\%-68\%) ${ }^{4}$ vs ICN $49 \%$ (95\% Cl, 38\%-61\%).

Combining the infliximab-only with the infliximab plus thiopurines treatment arms from the SONIC trial6 yielded a 26 week corticosteroid-free remission rate
TABLE 3 Rate Ratios For Initiator Trials Versus Non-Initiator Trials at 10, 26, and 52 Weeks of Follow-up

\begin{tabular}{|c|c|c|c|}
\hline \multirow[t]{2}{*}{ Outcome } & \multirow[t]{2}{*}{ Duration of Follow-up } & $\begin{array}{l}\text { Unadjusted Rate } \\
\text { Ratios }(95 \% \mathrm{Cl})\end{array}$ & $\begin{array}{c}\text { Adjusted Rate } \\
\text { Ratios }^{a}(95 \% \mathrm{Cl})\end{array}$ \\
\hline & & \multicolumn{2}{|c|}{ Initiator versus Non-Initiator Trials } \\
\hline \multirow[t]{2}{*}{ Clinical remission } & $26 w k$ & $1.44(1.17-1.77)$ & $1.53(1.20-1.96)$ \\
\hline & 52 wk & $1.46(1.22-1.74)$ & $1.52(1.23-1.89)$ \\
\hline \multirow{2}{*}{$\begin{array}{l}\text { Corticosteroid-free } \\
\text { remission }\end{array}$} & 26 wk & $1.73(1.38-2.16)$ & $1.74(1.33-2.29)$ \\
\hline & 52 wk & $1.63(1.35-1.97)$ & $1.62(1.28-2.04)$ \\
\hline
\end{tabular}

of $51 \%$, which contrasts with our study's estimate of $47 \%$. The unadjusted corticosteroid-free remission rate ratios for the contrast with the comparison groups were $1.69(95 \% \mathrm{Cl}, 1.31-2.17)$ for SONIC and $1.73(95 \% \mathrm{Cl}, 1.38-2.16)$ for ICN.

\section{DISCUSSION}

This study provides evidence that antiTNF $\alpha$ therapy given to pediatric patients who have moderate to severe CD in realworld settings is effective at achieving remission at rates comparable to singlegroup, open-label clinical trials, such as REACH, ${ }^{4}$ with pediatric patients and comparative controlled studies done with adults, such as SONIC. ${ }^{6}$ The treatment effect emerged as early as 6 weeks after initiation of therapy. In our analyses the outcome was achieved once a visit satisfied either the clinical or corticosteroid-free remission criteria, even if subsequently the patient may have experienced a worsening in disease activity. Thus, our results provide evidence on induction but not maintenance of remission.

There are important differences between our observational study and REACH and SONIC. Although we applied the REACH selection criteria to initiator trials, not all patients in our study were assessed at 10 weeks; instead, we allowed a patient to be assessed as late as 16 weeks to account for variation in visit frequency, which was at the discretion of patients and clinicians. Neither REACH nor our study were masked. The SONIC study was done with an adult sample, randomized and doubleblinded, and enrolled patients naïve to thiopurines.

Like an open-labeled randomized trial, the effect of treatment initiation in our nonrandomized trials tests the combination of pharmacological and behavioral effects induced by treatment awareness among clinicians and participants. Both patients and clinicians 

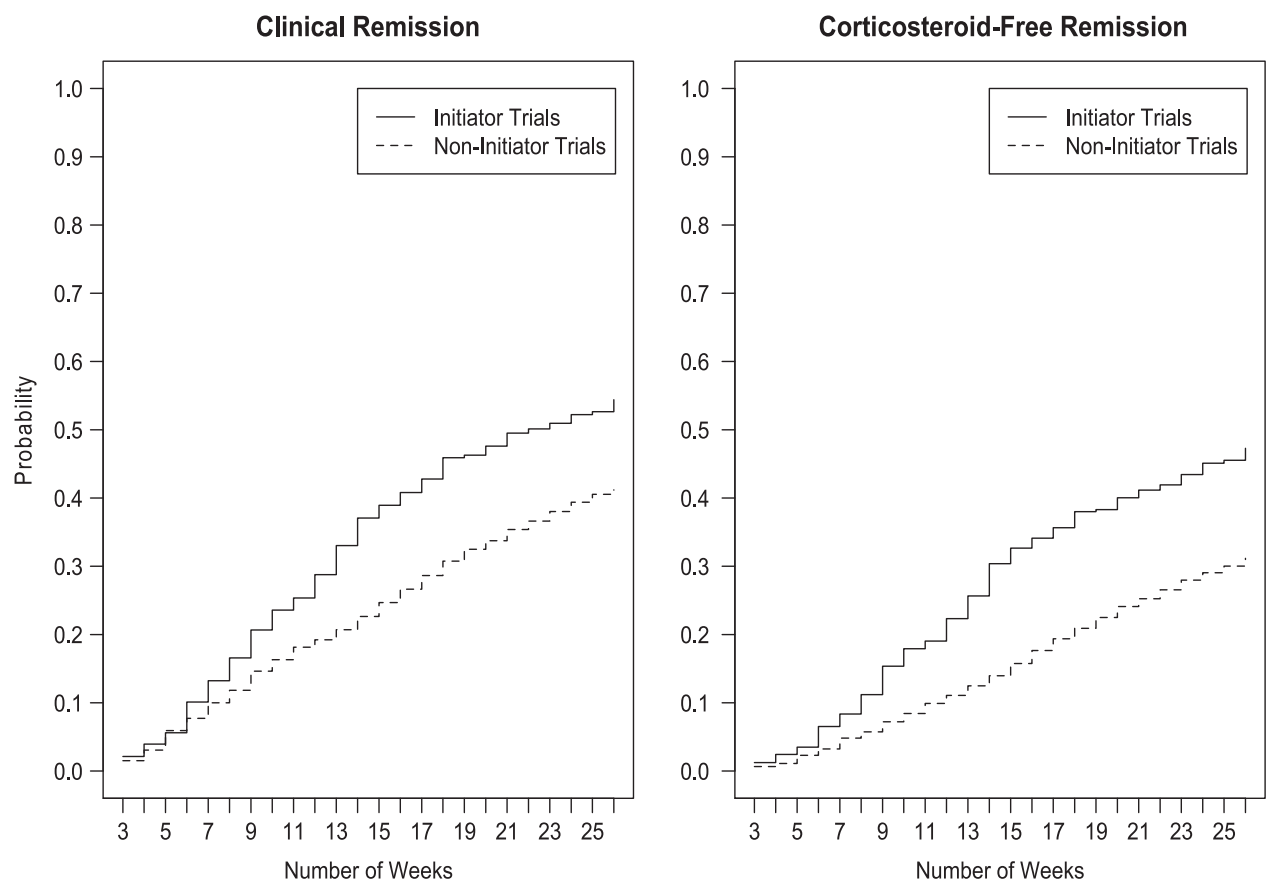

FIGURE 1

Cumulative probability of remission and corticosteroid-free remission for initiator and non-initiator trials during a 26-week follow-up period

were aware of the decision to use biologic therapy. For this reason, we preferred the use of the sPCDAl over the Physician Global Assessment of disease severity. The SPCDAl provided a more objective assessment of disease activity, whereas the Physician Global Assessment may have been subject to information bias, in which physicians factored use of biologics into their summary assessment of disease severity. It was reassuring that analyses using the Physician Global Assessment, which had less missing data, produced the same treatment effect estimates as the sPCDAl.

As the demand for comparative effectiveness evidence increases, new strategies for estimating treatment effects using observational data will be needed. This is particularly true for pediatrics, which frequently imports results of adult studies into its evidence base. The approach we used in this study to examine observational registry data as a sequence of nonrandomized trials is a promising methodology that can be extended to other clinical questions. ${ }^{28,29}$ The method allows generalization of likely benefits to patients as it avoids overly strict selection criteria that characterize explanatory clinical trials, which test efficacy and are not representative of real-world practice. ${ }^{32}$

One of our biggest concerns regarding the repurposing of the ICN registry data for research was missing data. We used $\mathrm{Ml}$, which assumes that data are missing at random and missingness is not informative. ${ }^{26}$ This assumption may not hold in our study, because it is possible that clinicians were less likely to perform some examinations in patients who had low disease activity. The similarity in treatment effects obtained with the sPCDAl and Physician Global Assessment of disease severity, which was present for nearly every visit, was reassuring. Unmeasured confounders, such as mucosal inflammation observed by endoscopy, may have positively influenced both the decision to initiate treatment and the level of disease activity; if this were the case, biologic treatment effectiveness would be underestimated. A fi- nal limitation is the potential for bias introduced by loss to follow-up. If this occurred at a greater frequency among anti-TNF $\alpha$ users in remission (less frequent follow-up among patients doing well) this would further underestimate treatment effectiveness.

\section{CONCLUSIONS}

Our findings suggest that anti-TNF $\alpha$ agents are comparatively more effective than usual care for treating children who have moderate to severe $C D$ who are managed in routine clinical practice settings. We have demonstrated that prospectively collected data from a large pediatric learning health system can be used to answer important clinical questions that cannot be addressed with controlled trials because of practical or ethical challenges. The study's methodology offers advantages relative to conventional clinical trials in terms of time, cost, recruitment, and the capacity to forgo use of placebo. Our results are remarkably consistent with those of single-group efficacy studies among 
children ${ }^{4}$ and comparative controlled clinical trials done among adults, ${ }^{4,6}$ but they expand the evidence base by providing new information on the comparative effectives of anti-TNF $\alpha$ for CD managed in routine pediatric gastroenterology settings.

\section{ACKNOWLEDGMENTS}

We thank the many gastroenterologists and their patients who made this study possible. Site leaders who merit special acknowledgment include: George Fuchs
(Arkansas Children's Hospital, Little Rock, AR); Mark Integlia (Barbara Bush Children's Hospital at Maine Medical Center, Portland, ME); Deborah Neigut (Children's Hospital Colorado, Aurora, C0); V. Mark Tsou (Children's Hospital of the King's Daughters, Norfolk, VA); William San Pablo (Children's Mercy Hospital, Kansas City, M0); Bess Schoen (Children's Healthcare of Atlanta Egleston, Atlanta, GA); Elawad Mamoun (Great Ormond Street Hospital, London, England); Deborah Cloney (Helen Devos
Children's Hospital, Grand Rapids, MI); lan Leibowitz (INOVA, Fairfax, VA); Victor Pineiro (Levine Children's Hospital, Charlotte, NC); Jacqueline Fridge (Northwest Pediatric Gastroenterology, Randall Children's Hospital, Portland, OR); Sabina Ali (Oakland Children's Hospital, Oakland, CA); John Grunow (Oklahoma University Health Sciences Center, Oklahoma City, OK); George Ferry (Texas Children's Hospital, Houston, TX); and Boris Sudel (University of Minnesota, Minneapolis, MN).

\section{REFERENCES}

1. Markowitz J, Grancher K, Kohn N, Lesser M, Daum F. A multicenter trial of 6-mercaptopurine and prednisone in children with newly diagnosed Crohn's disease. Gastroenterology. 2000;119(4):895-902

2. McDonald JW, Tsoulis DJ, Macdonald JK, Feagan BG. Methotrexate for induction of remission in refractory Crohn's disease. Cochrane Database Syst Rev. 2012;12: CD003459

3. Turner D, Grossman AB, Rosh J, et al. Methotrexate following unsuccessful thiopurine therapy in pediatric Crohn's disease. Am J Gastroenterol. 2007;102(12): 2804-2812; quiz 2803, 2813

4. Hyams J, Crandall W, Kugathasan S, et al; REACH Study Group. Induction and maintenance infliximab therapy for the treatment of moderate-to-severe Crohn's disease in children. Gastroenterology. 2007;132(3): 863-873, quiz 1165-1166

5. Peyrin-Biroulet L. Anti-TNF therapy in inflammatory bowel diseases: a huge review. Minerva Gastroenterol Dietol. 2010;56 (2): $233-243$

6. Colombel JF, Sandborn WJ, Reinisch W, et al; SONIC Study Group. Infliximab, azathioprine, or combination therapy for Crohn's disease. N Engl J Med. 2010;362 (15): 1383-1395

7. Odes S. How expensive is inflammatory bowel disease? A critical analysis. World $\mathrm{J}$ Gastroenterol. 2008;14(43):6641-6647

8. Parashette KR, Makam RC, Cuffari C. Infliximab therapy in pediatric Crohn's disease: a review. Clin Exp Gastroenterol. 2010;3:57-63

9. Adler J, Sandberg KC, Shpeen BH, et al. Variation in infliximab administration practices in the treatment of pediatric inflammatory bowel disease. J Pediatr Gastroenterol Nutr. 2013;57(1):35-38
10. Colletti RB, Baldassano RN, Milov DE, et al; Pediatric IBD Network for Research and Improvement. Variation in care in pediatric Crohn disease. J Pediatr Gastroenterol Nutr. 2009;49(3):297-303

11. Kappelman MD, Bousvaros A, Hyams J, et al. Intercenter variation in initial management of children with Crohn's disease. Inflamm Bowel Dis. 2007;13(7):890-895

12. Institute of Medicine. Initial National Priorities for Comparative Effectiveness Research. Washington, DC: The National Academies Press; 2009

13. Godwin M, Ruhland L, Casson I, et al. Pragmatic controlled clinical trials in primary care: the struggle between external and internal validity. BMC Med Res Methodol. 2003;3:28

14. Olsen LA, Aisner D, McGinnis JM, eds. The Learning Healthcare System: Workshop Summary. Washington, DC: The National Academies Press; 2007

15. Olsen LA, Saunders RS, McGinnis JM, eds. Patients Charting the Course: Citizen Engagement and the Learning Health System: Workshop Summary. Washington, DC: The National Academies Press; 2011

16. Grossmann C, Powers B, McGinnis JM, eds. Digital Infrastructure for the Learning Health System: The Foundation for Continuous Improvement in Health and Health Care: Workshop Series Summary. Washington, DC: The National Academies Press; 2011

17. National Research Council. Engineering a Learning Healthcare System: A Look at the Future: Workshop Summary. Washington, DC: The National Academies Press; 2011

18. Etheredge LM. A rapid-learning health system. Health Aff (Millwood). 2007;26(2): w107-w118
19. Friedman CP, Wong AK, Blumenthal D. Achieving a nationwide learning health system. Sci Trans/ Med. 2010;2(57):57cm29

20. Crandall W, Kappelman MD, Colletti RB, et al. ImproveCareNow: The development of a pediatric inflammatory bowel disease improvement network. Inflamm Bowel Dis. 2011;17(1):450-457

21. Crandall WV, Margolis PA, Kappelman MD, et al; ImproveCareNow Collaborative. Improved outcomes in a quality improvement collaborative for pediatric inflammatory bowel disease. Pediatrics. 2012;129(4). Available at: www.pediatrics.org/cgi/content/full/129/4/e1030

22. Kappelman MD, Crandall WV, Colletti RB, et al. Short pediatric Crohn's disease activity index for quality improvement and observational research. Inflamm Bowel Dis. 2011;17(1):112-117

23. Hyams J, Markowitz J, Otley A, et al; Pediatric Inflammatory Bowel Disease Collaborative Research Group. Evaluation of the pediatric crohn disease activity index: a prospective multicenter experience. $J$ Pediatr Gastroenterol Nutr. 2005;41(4):416421

24. Stuart EA, Azur M, Frangakis C, Leaf $P$. Multiple imputation with large data sets: a case study of the Children's Mental Health Initiative. Am J Epidemiol. 2009;169(9): 1133-1139

25. Baraldi AN, Enders CK. An introduction to modern missing data analyses. J Sch Psychol. 2010;48(1):5-37

26. Rubin DB. Multiple Imputation for Nonresponse in Surveys. Hoboken, NJ: Wiley; 1987

27. Allison P. Imputation of Categorical Variables with PROC MI: SAS Users Group International. SUGI; 2005. Available at: www2.sas.com/ 
proceedings/sugi30/113-30.pdf. Accessed May 7, 2014

28. Danaei G, Rodríguez LA, Cantero OF, Logan R, Hernán MA. Observational data for comparative effectiveness research: an emulation of randomised trials of statins and primary prevention of coronary heart disease. Stat Methods Med Res. 2013;22(1): 70-96
29. Hernán MA, Alonso A, Logan R, et al. Observational studies analyzed like randomized experiments: an application to postmenopausal hormone therapy and coronary heart disease. Epidemiology. 2008;19(6):766-779

30. Laupacis A, Sackett DL, Roberts RS. An assessment of clinically useful measures of the consequences of treatment. $N$ Engl J Med. 1988;318(26):1728-1733
31. Altman DG. Confidence intervals for the number needed to treat. BMJ. 1998;317 (7168):1309-1312

32. Ha C, Ullman TA, Siegel CA, Kornbluth A. Patients enrolled in randomized controlled trials do not represent the inflammatory bowel disease patient population. Clin Gastroenterol Hepatol. 2012;10(9):10021007

(Continued from first page)

\title{
KEY WORDS
}

Crohn disease, comparative effectiveness research, anti-tumor necrosis factor- $\alpha$, child

\author{
ABBREVIATIONS \\ anti-TNF $\alpha$-anti-tumor necrosis factor- $\alpha$ \\ CD-Crohn disease \\ $\mathrm{Cl}$-confidence interval \\ IBD-inflammatory bowel disease \\ ICN-ImproveCareNow \\ MI-multiple imputation \\ NNT-number needed to treat \\ sPCDAI—Short Pediatric Crohn Disease Activity Index
}

Dr Forrest was responsible for study concept and design, analysis and interpretation of data, statistical analysis, study supervision, and drafting of the manuscript, and obtained funding; Dr Crandall was responsible for study concept and design, acquisition of data, analysis and interpretation of data, and critical revision of the manuscript, and obtained funding; Dr Bailey was responsible for study concept and design, analysis and interpretation of data, critical revision, and statistical analysis, and obtained funding; Dr Zhang was responsible for study concept and design, analysis and interpretation of data, critical revision, and statistical analysis; $\mathrm{Dr}$ Joffe was responsible for study concept and design, analysis and interpretation of data, critical revision, and statistical analysis, and obtained funding; Dr Colletti was responsible for study concept and design, acquisition of data, analysis and interpretation of data, critical revision, and study supervision, and obtained funding; Drs Adler, Baron, Berman, del Rosario, Grossman, Hoffenberg, Israel, Kim, Lightdale, Mehta, Milov, Patel, and Tung were responsible for study concept and design, acquisition of data, and critical revision; Dr Margolis was responsible for study concept and design, acquisition of data, critical revision, and study supervision, and obtained funding; Dr Marsolo was responsible for study concept and design, acquisition of data, and critical revision, and obtained funding; Dr Kappelman was responsible for study concept and design, acquisition of data, analysis and interpretation of data, critical revision of the manuscript, and obtained funding; and all authors approved the final manuscript as submitted.

All authors agree to be accountable for all aspects of the work.

www.pediatrics.org/cgi/doi/10.1542/peds.2013-4103

doi:10.1542/peds.2013-4103

Accepted for publication Apr 14, 2014

Address correspondence to Christopher B. Forrest, MD, PhD, Professor, Department of Pediatrics, Children's Hospital of Philadelphia, 34th St and Civic Center Blvd, Philadelphia, PA 19004. E-mail: forrestc@email.chop.edu

PEDIATRICS (ISSN Numbers: Print, 0031-4005; Online, 1098-4275)

Copyright (C) 2014 by the American Academy of Pediatrics

FINANCIAL DISCLOSURE: Dr Colletti has been a consultant to Janssen Biotech and serves on its scientific advisory, and has served on an AbbVie advisor board; Dr Kim has served as a consultant to Abbott; Dr Patel has received speaker fees from Abbott and Janssen Biotech; Dr Kappelman has received research support from Janssen Biotech and has served as a consultant to AbbVie; the other authors have indicated they have no financial relationships relevant to this article to disclose.

FUNDING: Supported by a grant from the Agency for Healthcare Research and Quality (R01 HS020024). Dr Kappelman was supported by a grant from the National Institute of Diabetes and Digestive and Kidney Diseases (K08 DK088957). The study sponsors had no role in the study design or the collection, analysis, and interpretation of data

POTENTIAL CONFLICT OF INTEREST: Dr Crandall reports consulting fees from Boehringer Ingelheim Pharma GmbH \& Co, KG, research support from AbbVie, and a sponsored visiting professorship from Meade Johnson; Dr Colletti has been a consultant to Janssen Biotech and serves on its scientific advisory, has served on an AbbVie advisor board, and serves as a consultant for Accordant Health Services; Dr Kim has served as a consultant to Abbott; Dr Patel has received speaker fees from Abbott and Janssen Biotech; Dr Kappelman reports stock holding in Johnson and Johnson; the other authors have indicated they have no potential conflicts of interest to disclose

COMPANION PAPER: A companion to this article can be found on page 171, and online at www.pediatrics.org/cgi/doi/10.1542/peds.2014-1182. 